\title{
Motes enhance data recovery from satellite-relayed biologgers and can facilitate collaborative research into marine habitat utilization
}

\author{
Tiphaine Jeanniard-du-Dot ${ }^{1,4^{*}}$ (D) Kim Holland ${ }^{2}$, Gregory S. Schorr ${ }^{3}$ and Danny Vo ${ }^{1}$
}

\begin{abstract}
Background: The fields of biologging and telemetry have triggered significant advances in the understanding of animal behavior, physiological ecology and habitat utilization. Biologging devices ("tags") can also measure aspects of the physical and biological characteristics of the animals' environment. As marine ecosystems are less accessible than terrestrial ones and marine animals more elusive and difficult to study, data collected by tags attached to marine animals often have to be relayed via satellite. However, satellite availability is not continuous and decreases with decreasing latitude. Consequently, collection of sufficient data is even more challenging in the tropics and mid-latitudes than at the poles. To overcome this limitation and increase data throughput from biologgers, new land-based receiving stations (called Motes) that can receive, log and relay messages from devices transmitting on the Argos satellite frequency have been developed.

Methods: We investigated the performance of Motes as enhancers of recovery of signals transmitted by tags normally destined for satellite relay. We quantified Mote reception range, coverage area, data throughput and data corruption rates and examined factors that might impact these parameters. To do so, we used all signals detected by two arrays of Motes installed in the Hawaiian Islands and in Southern California between latitudes 22 and $33^{\circ} \mathrm{N}$. Second, using data from 12 sharks and 12 whales tagged near the two Mote arrays, we assessed how increased data recovery translated into improved ability to interpret the behavior of the tagged animals.

Results: Motes were capable of receiving up to $100 \%$ of messages transmitted within their reception range and overall presented a three- to fivefold increase in data message recovery compared to satellites alone. Message reception performance of Motes depended on their coverage area which in turn was affected by station elevation, the presence or not of obstacles within their line of sight, and the directionality of antennas.

Conclusions: The increased quantity of data enabled improved biological interpretation of the animals studied. As such, Motes can improve our knowledge of marine animals' ecology in relation to their physical and biological environments. Large-scale Mote arrays could potentially facilitate collaborative multi-disciplinary research projects, resulting in better ecosystem conservation and management.
\end{abstract}

Keywords: Biologging, New technology, Mote, Satellite, Argos, Remote sensing

\section{Background}

Oceanic environments and marine animals are inherently difficult to study, and there are significant challenges

\footnotetext{
*Correspondence: tiphainejdd@gmail.com

${ }^{4}$ Present Address: Department of Fisheries and Oceans, Institut Maurice Lamontagne, P.O. Box 1000, 850 Route de la Mer, Mont-Joli, QC G5H 3Z4, Canada

Full list of author information is available at the end of the article
}

involved with acquiring observational data at the scales and resolutions required to elucidate important conservation issues such as habitat preferences and the way that those preferences will be impacted by climate change [32]. In the last 25 years, the field of animal telemetry (i.e., remote acquisition of data using loggers and transmitters deployed on free-ranging animals) has allowed insight 
into the movements and behaviors of individual animals and their habitat use even in the most remote regions of the oceans $[26,40]$. An increasing variety of on-board sensors has shed light on movement patterns, dive profiles, triaxial acceleration, speed, heart rate and body temperature (among others) of these focal animals and on aspects of their immediate surroundings (e.g., salinity, temperature, light, fluorescence, dissolved oxygen or sound levels). This wide breadth of new knowledge helps advance research in the fields of physiology, ecology and physical oceanography, and informs and influences conservation and management policies worldwide $[3,4]$.

High-resolution data archives can be reliably retrieved from marine animals tagged with short-duration tags (e.g., suction cup attached) or that haul-out at known locations [17, 27, 41]. Also, for heavily exploited fish species, fish-borne archiving tags can be recovered in moderate numbers [7, 29]. However, in general (and especially for real and near-real time applications), archived data from fishes and marine mammals have to be acquired via transmissions picked up and relayed by orbiting satellites. Satellite-based telemetry devices usually connect to the Argos system using platform terminal transmitters (PTT). These PTTs transmit ultra-high frequency signals $(401.65 \mathrm{MHz} \pm 30 \mathrm{kHz})$ in pulses that can be detected by satellites from the Argos network when their orbit passes over the tag. The location of the animal is then calculated by the Argos processing system by measuring the Doppler shift in the radio frequency of transmissions from the PTT due to the movement of the satellite relative to the tag [15]. Enhanced PTTs can also transmit encoded messages that carry additional information such as more precise GPS locations or other on-board processed data acquired from various sensors. However, there are two limitations to this system. First, data can only be transmitted at a very small bandwidth ( $\sim 32$ bytes/message, one message every $10-60 \mathrm{~s}$ ), which greatly limits the resolution of transmitted data. Second, Argos satellite availability can be very limited spatially and temporally. Because of their polar orbits, each Argos satellite passes approximately five times more often at the poles compared to the equator (14 times vs. 3-4 times [15]). Consequently, the probability of a successful satellite connection is significantly lower at the equator ( $12 \%$ for a single signal) than at the poles (Fig. 1). It also changes with time of day with virtually no satellite coverage between approximately 10.00 p.m. and midnight or 10.00 a.m. and noon UTC between latitudes $20^{\circ}-30^{\circ} \mathrm{N}$ at longitudes $\sim 150^{\circ} \mathrm{W}$ for example (Fig. 1, Source: http://www.argos-system.org [2]).

There are two basic types of satellite-linked tags for use on marine animals. One type is known as pop-up archival tags (PATs) and is predominantly used to track largescale movements of marine animals at sea, especially those that do not break the surface or where there is no rigid surface for tag attachment (e.g., most teleost fishes $[11,34,39])$. The data collected by these tags are often several weeks old when they are transmitted to satellite, and position estimates between the release site and the pop-up site are based on light-based geolocation methods using light levels measured and stored by the tag [31]. Following release, the tags float at the surface for several days and cycle through the same data for transmission multiple times to maximize data throughput. The other major category of tags is those mounted on the external surface of animals such as the dorsal fins of sharks and whales, the carapace of turtles or the fur of seals, and that attempt to transmit whenever the animal breaks the ocean surface [20]. These tags can provide near-real time positional fixes and a modest amount of behavioral and environmental data. However, because many marine animals are seldom at the surface and often only for short periods of time, successful uplinking of the data can be challenging [21,30]. Adaptive tag programming (re-transmit rate, buffer specifications, restricted dive definitions, etc.) could help improve likelihood of successful data recovery, albeit at the expense of more summarized data (for any tag with limited battery capacity, higher numbers of a single data message transmission would result into a lower number of unique data messages sent over the duration of the battery life). Researchers are often faced with the choice of balancing the desire for higher-resolution data (and therefore more Argos messages per day) with the desire for a complete low-resolution record of a tagged animal's behavior. Similarly, because Argos-derived locations from Doppler shift depend in part on the number of successive messages received by a satellite, accurate positional fixes can be rare for animals that surface infrequently. In summary, collecting sufficient and meaningful data for tagged marine animals via the Argos system can be extremely challenging regardless of the type of tag used and this is even more so at low latitudes. Thus, there is a pressing priority to improve data throughput for marine animals.

To this end, new stationary, fully autonomous groundbased listening and data relay stations called Motes (Wildlife Computers ${ }^{\mathrm{TM}}$ ) have been designed to augment the Argos system and improve data throughput from tagged animals (Fig. 2). The goals are to increase the percentage of received satellite messages to $100 \%$ within Mote reception range and to augment the data throughput typically obtained through traditional Argos satellite transmission uplinks. Such an enhancement of data volume would result in finer understanding of the behavioral and environmental data collected by the tags. The objectives of this preliminary study were to investigate how these receiving stations may improve data throughput 


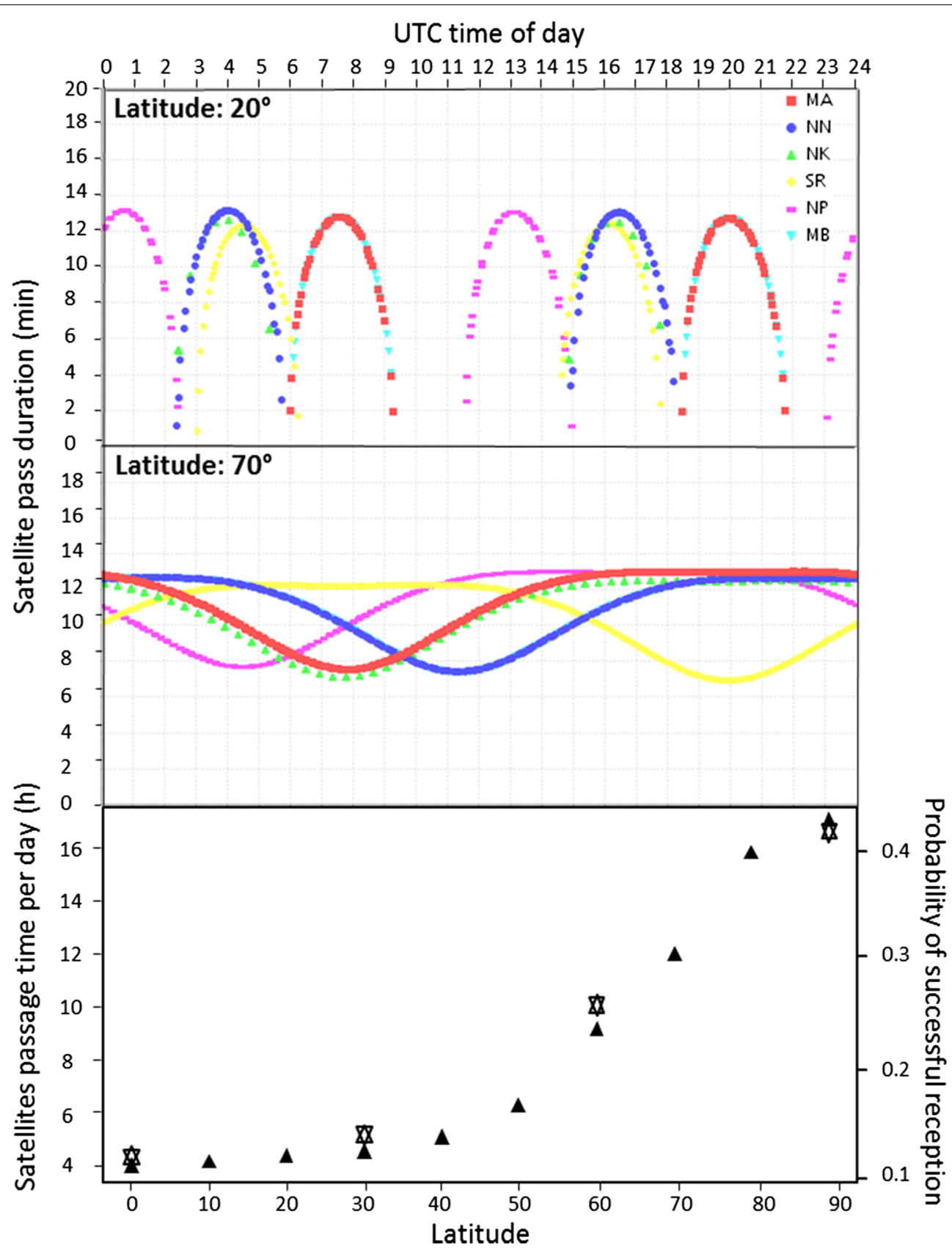

Fig. 1 Satellite pass durations at latitude $20^{\circ}$ and $70^{\circ}$ per time of day (top and middle panels, each color represents a specific satellite), and Argos satellites cumulated passage time per day (in hours, closed triangles) as well as probability of successful reception of a single (no re-transmit) satelliterelayed message by Argos satellites (open stars) as a function of latitude (lower panel). Source http://www.argos-system.org [2]

from tagged animals compared to the satellite-relayed system and to determine what factors influence performance parameters such as detection range and volume of data recovered. We also assessed how increased data throughput can improve biological interpretation of tagged animals behaviors. To accomplish these goals, we first described hardware specifics and reception characteristics of two currently available Mote arrays. Second, we analyzed data collected by Mote stations from two ongoing pilot studies on tiger sharks (Galeocerdo cuvier) around the Hawaiian Islands, and on Cuvier's beaked whales (Ziphius cavirostris) and fin whales (Balaenoptera physalus) in Southern California (three species for which a lack of scientific data hinders conservation and/or management efforts, $[6,36,37])$, and compared them to data collected by Argos satellites only. 


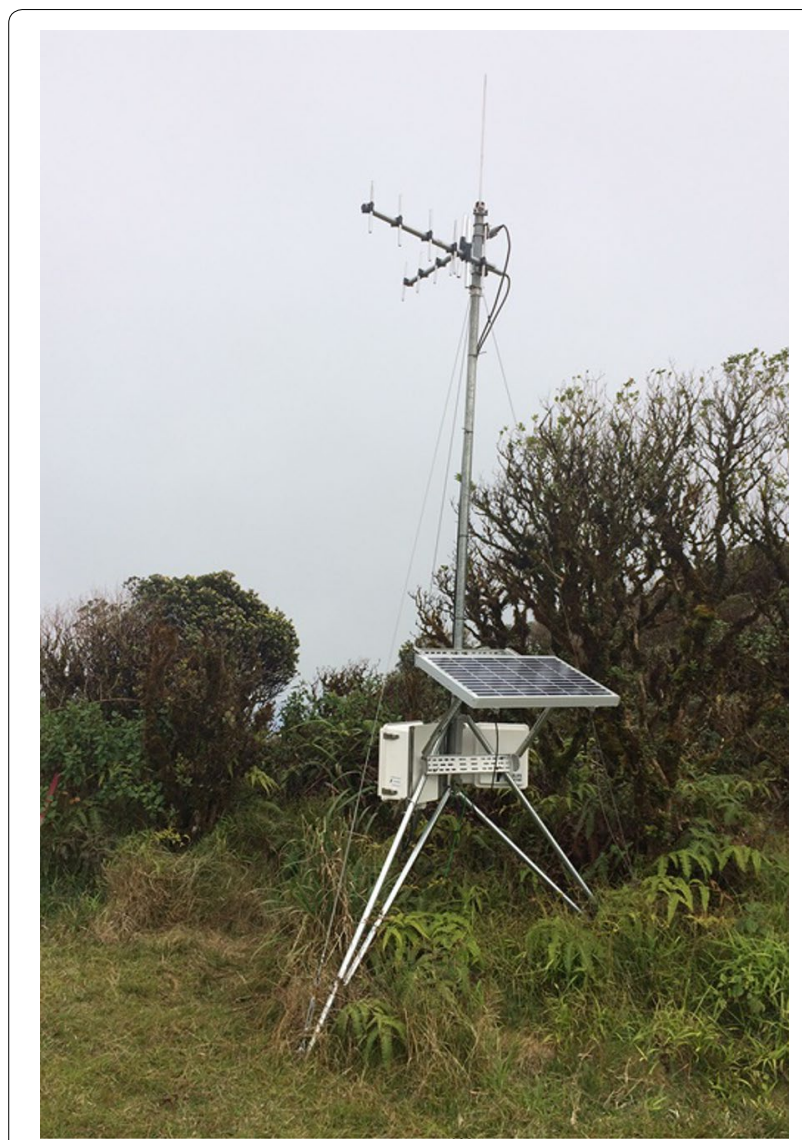

Fig. 2 Picture of a Mote (Wildlife Computers ${ }^{\mathrm{TM}}$ ) with the two independent directional receiving antennas, the solar panel for a constant supply source, and the receiving unit visible

\section{Methods}

Technical specifications

The basic element of land-based receivers (Motes) is one or two directional antenna(s) tuned to the same frequency as the Argos satellite system (401 MHz, Fig. 2). Omni-directional antennas can also be used to cover a wider azimuth range, but, practically, these have a much reduced detection range. The antenna(s) is(are) connected to a signal processor for archiving the received messages. The archived messages can be physically downloaded or relayed via Ethernet connection, Wi-Fi, or GSM modem before decoding and archiving on the Wildlife Computers' Data Portal. The frequency of relay of archived messages can be user-determined. The antennas, processors and power supply (photovoltaic or from the grid) can be installed on self-contained tripods or attached to existing structures. Complete technical specifications of Motes can be found in Additional file 1: Doc. S1 (Motes are commercially available from Wildlife Computers $^{\mathrm{TM}}$ ).

Motes are non-discriminatory and log any type of Argos-intended messages from any PTT ID within their range. Data are then encrypted and transferred onto the wildlife computers cloud storage and can be accessed, visualized, manipulated, downloaded and shared through their Data Portal. Data rights of tag owners are respected thanks to a privacy system in which a specific PTT data is only shared to an end-user if he/she has provided their Argos information to Wildlife Computers ${ }^{\mathrm{TM}}$. In this case, their dataset is automatically augmented with Mote data if available. Otherwise, unclaimed data remain anonymous and private.

\section{Performance testing}

This preliminary study investigates the performance of two Mote "arrays" of two or three Mote units each. Both arrays are installed in tropical or subtropical areas (Table 1). In Southern California, Mote $14 \mathrm{X} 0011$ is installed on San Nicolas Island $\left(33^{\circ} 14^{\prime} 56^{\prime \prime} \mathrm{N}\right.$, $\left.119^{\circ} 31^{\prime} 21^{\prime \prime} \mathrm{W}\right)$ at an elevation of $275 \mathrm{~m}$ with antennas A and $\mathrm{B}$ facing northeast (bearing $20^{\circ}$ ) and southeast (bearing $130^{\circ}$ ), respectively. Mote $13 \mathrm{X} 0002$ is installed on San Clemente Island $\left(32^{\circ} 53^{\prime} 45^{\prime \prime} \mathrm{N}, 118^{\circ} 27^{\prime} 47^{\prime \prime} \mathrm{W}\right)$ at an elevation of $575 \mathrm{~m}$ with antennas $\mathrm{A}$ and $\mathrm{B}$ facing northwest

Table 1 Details of the locations, deployment features (elevation of the Mote and duration of deployment) and performance characteristics (number of PTTs detected, maximum distance of reception, coverage area where Motes received $100 \%$ of the same messages received by Argos satellites, and maximum angle of message detection) for the two Motes of the Southern California array (SoCal) and the three Motes of the Hawaiian array

\begin{tabular}{|c|c|c|c|c|c|c|c|c|}
\hline Location & Mote & Elevation (m) & Duration (h) & \# uplinks (h) & \# PTTs & Distance (km) & $100 \%$ coverage area $\left(\mathrm{km}^{2}\right)$ & Angle $\left({ }^{\circ}\right)$ \\
\hline \multicolumn{9}{|l|}{ SoCal } \\
\hline San Clemente & $13 \times 0002$ & 577 & 3726 & 92 & 186 & 142 & 3564 & 360 \\
\hline San Nicolas & $14 \times 0011$ & 227 & 17,151 & 12 & 221 & 207 & 2376 & 360 \\
\hline \multicolumn{9}{|l|}{ Hawaii } \\
\hline Maui & $14 \times 0003$ & 820 & 14,617 & 20 & 156 & 85 & 2574 & 145 \\
\hline Maui & $14 \times 0005$ & 88 & 14,257 & 32 & 98 & 25 & 1001 & 139 \\
\hline Kauai & $15 \times 0010$ & 446 & 534 & 11 & 20 & 43 & 1430 & 176 \\
\hline
\end{tabular}


(bearing $290^{\circ}$ ) and southwest (bearing $245^{\circ}$ ), respectively. There is no direct obstruction in the line of sight of either Mote. The two-channel receivers are packaged in Campbell Scientific ENC12/14 enclosures, and logged data have to be retrieved manually with an external thumb drive.

The second "array" is located on the islands of Maui and Kauai, Hawaii. One unit (14X0003) is a free-standing tripod-mounted unit installed on a rocky berm overlooking Lahaina $\left(20^{\circ} 51^{\prime} 29^{\prime \prime} \mathrm{N} 156^{\circ} 39^{\prime} 00^{\prime \prime} \mathrm{W}\right)$ at an elevation of $88 \mathrm{~m}$ with directional (6-element Yagi) antennas facing southwest (bearing $226^{\circ}$ ) and north (bearing $323^{\circ}$ ). The second unit (14X0005) is installed on a roof-top mounted pole on a house in Kula, Maui $\left(20^{\circ} 45^{\prime} 47^{\prime \prime} \mathrm{N} 156^{\circ} 19^{\prime} 48^{\prime \prime} \mathrm{W}\right)$, at an elevation of $820 \mathrm{~m}$ with antennas facing south (bearing $185^{\circ}$ ) and west (bearing $264^{\circ}$ ). Motes $14 \mathrm{X0003}$ and 14X0005 are 2-channel receivers packaged in Campbell Scientific ENC12/14 enclosures, plugged into house power and transferring data at 15-min intervals via Wi-Fi connectivity to the Wildlife Computers Data Portal. The third Hawaiian Mote is installed on Kauai Island on February 10, 2016 (15X0010: $22^{\circ} 08^{\prime} 06^{\prime \prime} \mathrm{N}, 159^{\circ} 43^{\prime} 44^{\prime \prime} \mathrm{W}$, elevation $446 \mathrm{~m}$ ), with antennas facing southwest (bearing $220^{\circ}$ ) and north (bearing $310^{\circ}$ ). Hawaiian Islands being volcanic, all Motes had mountains blocking them from receiving signals to their north or northwest (Fig. 3). Kaho'olawe, Lanai and Molokai Islands also obstruct their line of sight. We analyzed data from deployment time to March 20, 2016, for all Motes.

Methods to assess Mote performance fell into two basic categories (1) spatial area $\left(\mathrm{km}^{2}\right)$ and range of detection $(\mathrm{km})$ and (2) efficacy of data throughput. We used successful receptions obtained from transmitters operational in the area to determine the spatial dimensions and coverage area within which $100 \%$ of transmissions successfully received by Argos satellites were also detected by a Mote. Argos location classes of 1, 2 and 3 were used for this study to minimize spurious location estimates, and only Mote messages received within $1 \mathrm{~s}$ of the Argos reception were assigned to that location estimate. The Argos location estimates for each of the transmissions received were then plotted on a grid comprised of $0.1^{\circ}$-side squares. We then determined the $100 \%$ coverage area by multiplying the number of $100 \%$ reception grid squares by their respective areas $\left(\sim 143 \mathrm{~km}^{2}\right.$ at $22^{\circ} \mathrm{N}$ in Hawaii $[\sim 11 \mathrm{~km} \times 13 \mathrm{~km}]$, and $99 \mathrm{~km}^{2}$ at $33^{\circ} \mathrm{N}$ in Southern California [ 11 km $\times 9 \mathrm{~km}])$. Data used for this analysis did not include messages collected only by Motes because no geographical location can be assigned to them (no Doppler effect). We also measured the maximum distance at which Motes successfully received a message (in $\mathrm{km}$ ), as well as the maximum angle between two received messages (i.e., the locations of the two transmission points the furthest apart on an ellipse with the Mote at the center in ${ }^{\circ}$ ).

Relationship between coverage areas and site parameters (elevation in $\mathrm{m}$ and location) and between numbers of uplinks per hour and coverage area was investigated using linear regressions (lm in R package "stats", $n=5$ ). These models are based on a low sample size and thus had a resulting low degree of freedom. It also meant that model assumptions were difficult to assess, although we assumed normality and homoscedasticity given the moderate deviations observed in the distribution of the residuals. We are aware of these limitations, but are still providing results as illustrative trends. Selected models were:

$$
\begin{aligned}
& \text { Cover.area } \sim \beta_{0}+\beta_{1} \text { Elevation }+\beta_{2} \text { Location }+\varepsilon \\
& \text { Uplink.rate } \sim \beta_{3}+\beta_{4} \text { Cover.area }+\varepsilon
\end{aligned}
$$

The improvement in Argos message recovery rate by Motes was assessed using a floating MiniPAT tag that drifted at the water surface within the range of Mote $14 X 0003$ near Maui Island for $44 \mathrm{~h}$ (Sept 18, 2015, at 10:06 p.m. to Sept 20, 2015, at 5:39 p.m.). This type of floating tag repeatedly transmits previously recorded data at the rate of one message per min. It also sends "status messages" that indicate the total number of transmission attempts actually made by the tag (regardless of whether or not they were actually received). We calculated the proportion of messages transmitted that were successfully received by either the Mote or Argos satellites within the period of time during which the tag was in the reception range of the Mote. This was calculated by dividing the number of received messages by each platform by the total number of transmitted messages. Calculations also took into account the corruption rate, i.e., the difference of received messages compared to successfully decoded messages for both Mote and the Argos satellite receivers. Finally, similar messages are repeatedly transmitted as the tags cycle through their message buffer. Consequently, an increase in message reception does not necessarily translate into a linear increase in data recovery. We took into account duplicate messages received to calculate actual data recovery.

\section{Case studies}

We investigated how the increase in amount of data collected through Motes enhanced interpretation of behaviors being exhibited by the animals carrying satellite tags. We used case studies involving 12 tiger sharks in Hawaii and 10 Cuvier's beaked whales and two fin whales in Southern California. Adult sharks were tagged around Maui from March 2012 to February 2016 and stayed in the vicinity of Motes for most of the deployment time (Additional file 1: Table S1). Four of these sharks were 


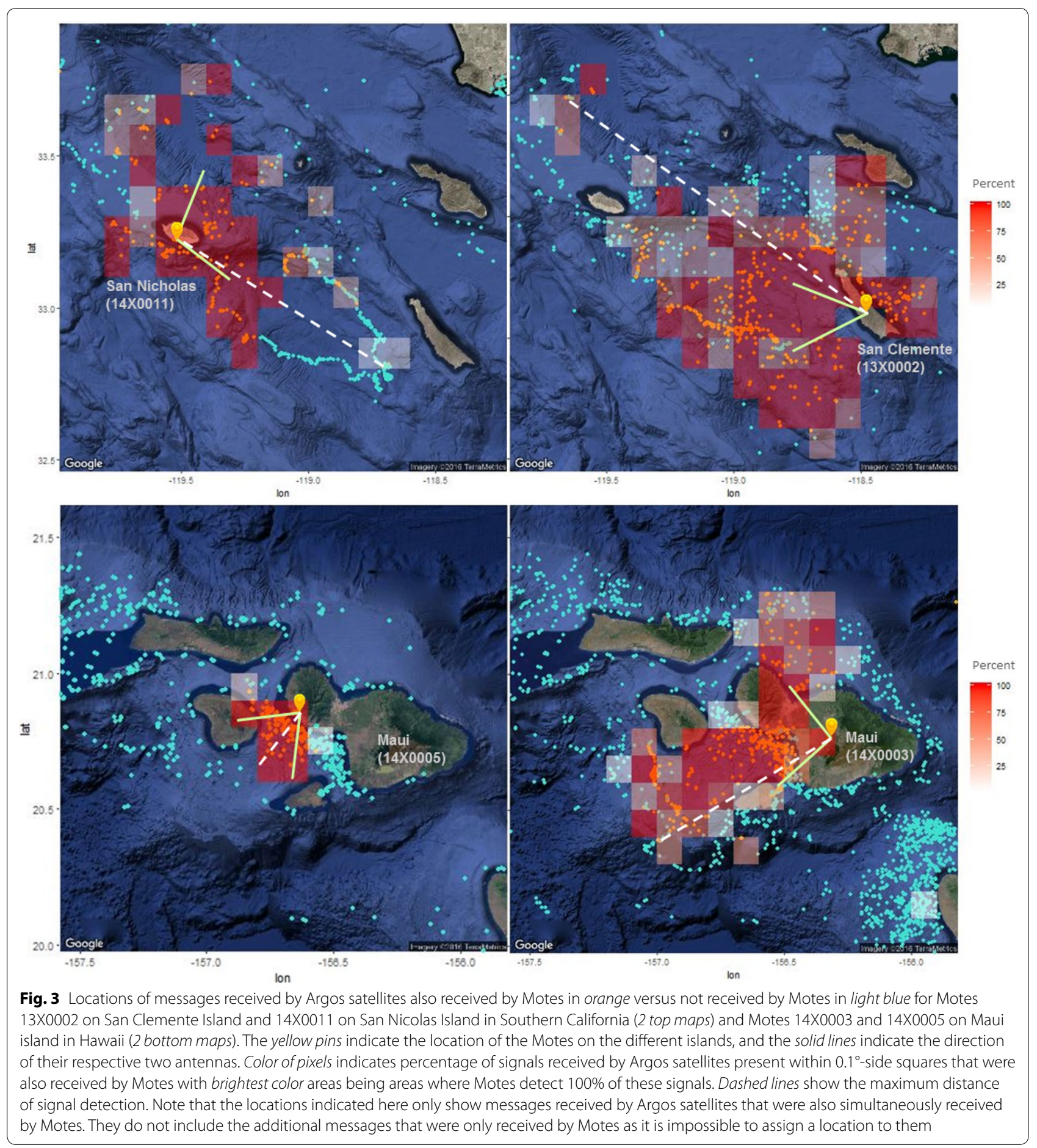

equipped with SPLASH tags (Wildlife Computers ${ }^{\mathrm{TM}}$ ) that recorded depth $( \pm 0.5 \mathrm{~m})$ and/or external temperature $\left({ }^{\circ} \mathrm{C}\right)$ every $1.25,5$ or $10 \mathrm{~min}$ for $62-1055$ days. Four other animals were equipped with SPOT5 tags, and two with Fastloc-enabled SPOT6-F (Wildlife Computers ${ }^{\mathrm{TM}}$ ) that recorded GPS locations for 70-760 days. Two additional sharks were tagged with Wildlife Computers ${ }^{\mathrm{TM}}$ SCOUT tags (for 2 and 182 days) which recorded GPS locations and dive depths of the animals, as well as oceanographic data (compressed mixed-layer depth and temperature, see Additional file 1: Table S1 for details). Ten Cuvier's beaked whales and two fin whales were tracked in 
Southern California for 8-57 days from January 2014 to February 2016 and remained in the range of the California Mote array for most of their deployment time (Additional file 1: Table S1). They were all equipped with SPLASH tags that recorded dive start and end times, dive duration, maximum dive depth and dive shape. They also recorded time-series of dive depth every $2.5 \mathrm{~min}$ for $24 \mathrm{~h}$ every 6 days. User defined Argos settings for tags used in sharks and whales are detailed in Additional file 1: Table S1.

Number and rates of uplinks received, percentage of successful message decoding and number of GPS locations or dive data acquired were calculated independently for Motes and Argos over the time of tag deployments. We calculated how many messages were received multiple times by looking at duplicate messages, the overlap in message reception by the two independent Mote antennas, and/or the overlap in messages received simultaneously by Motes and Argos satellites. The proportion of behavioral information collected by Motes or Argos satellites was calculated by pooling all data available for a specific animal and calculating the relative contribution to this total by one or the other of the receiving platform types. The effect of low satellite coverage at specific times of day was investigated by calculating the difference in numbers of uplinks within each hour of the day received either from Motes or from Argos satellites sources. Statistical differences between Mote and Argos satellite performances or between different Mote array locations and/or species were tested with Wilcoxon signed-rank test for paired samples, and significance level was set at 0.05 ( $\mathrm{n}=12$ sharks in Hawaii, $\mathrm{n}=12$ whales in SoCal each with a Mote and Argos value). All values reported below are mean \pm SD.

\section{Results}

\section{Mote performance testing}

Maximum distance at which Motes were capable of receiving Argos messages varied from 25 to $207 \mathrm{~km}$. The $100 \%$ reception coverage area for individual Motes ranged from 1001 to $3564 \mathrm{~km}^{2}$ and their reception angle from $140^{\circ}$ to $360^{\circ}$ depending on the characteristics of antennas' orientation and of the deployment site. In general, Motes deployed in Southern California had longer and wider reception ranges than Motes on Hawaiian Islands which had constraints on lateral coverage caused by terrain shielding (Table 1; Fig. 3). The number and rate of messages received also varied by Mote and by location (Hawaii vs. Southern California). In Southern California, Mote 13X0002 recorded $\sim 9$ times more Argos messages than Mote 14X0011 ( 92 vs. 12, Table 1). Once again, rate of messages received per hour was lower overall for Hawaiian Motes with 14X0003 (with the longest and widest reception range) receiving $\sim 20$ messages per hour, while 14X0005 (with the shortest reception range) only logging three messages per hour (Table 1).

Coverage area (coverage of reception of $100 \%$ of signals, in $\mathrm{km}^{2}$ ) increased with Mote deployment site elevation and its location (adj. $R^{2}=0.90$, model $p=0.049$, Fig. 4a). Slope of the relationship between coverage area and elevation was similar for both locations $\left(\beta_{1}=2.41 \pm 0.56\right.$, $p=0.050$ ), but the coverage area was approximately twice greater at a given elevation in Southern California compared to Hawaii $\left(\beta_{0}=578.69\right.$ and $\beta_{2}=1362.82$ for Southern California, $p=0.206$ and $p=0.042$, respectively). Performance of Motes at receiving messages shows a trend in which number of uplinks per hour was in turn positively related to coverage area although significance was not reached (adj. $R^{2}=0.71, \beta_{4}=0.03$, $p=0.071$, Fig. 4b). Model assumptions were tested, but even though we did not observe major deviations from normality or homoscedasticity in the distribution of residuals (within the limits of $n=5$ ), the low degree of freedom and lack of power mean that probability of type II errors are increased.

One MiniPAT that released from a tiger shark drifted at the water surface within the range of Mote 14X0003 on Maui Island from Sept 18, 2015, at 10:06 p.m. to Sept 20, 2015, at 5:39 p.m. (Fig. 5). During this time period, it transmitted 2613 messages (one message every $60 \mathrm{~s}$ ). Mote 14X0003 recorded 1728 messages out of the 2613 transmitted and successfully decoded $79 \%$ of them. The rate of recovery of the transmitted messages varied with the tag's location within the Mote reception range and peaked at $85-100 \%$ recovery when line of sight was the clearest (Fig. 5). During the same period of time, Argos satellites received only 482 messages and successfully decoded $85 \%$ of them. Consequently, Mote 14X0003 received 3.3-4.7 times more transmitted messages than Argos satellites within the same time-frame. The percentage of successful uplinks from Argos satellites was $\sim 16 \%$ of transmitted signals compared to $\sim 52 \%$ from the Mote over the same time-frame (and up to $100 \%$ at times, Fig. 5). Unique data messages can be received multiple times as the tag cycles through its message buffer. Taking into account these duplicate receptions, the Mote logged $85 \%$ of the unique data generated on the tag, while Argos captured only $30 \%$.

\section{Case studies}

In the case of tags deployed on diving animals (thus transmitting only sporadically when animals resurface), Motes logged overall $4.5 \pm 3.0$ times more messages than Argos satellites (range 0.7-12.4, $W=422, p=0.005$ ) over the course of tags' deployments. This increase in message reception was slightly but not significantly greater 


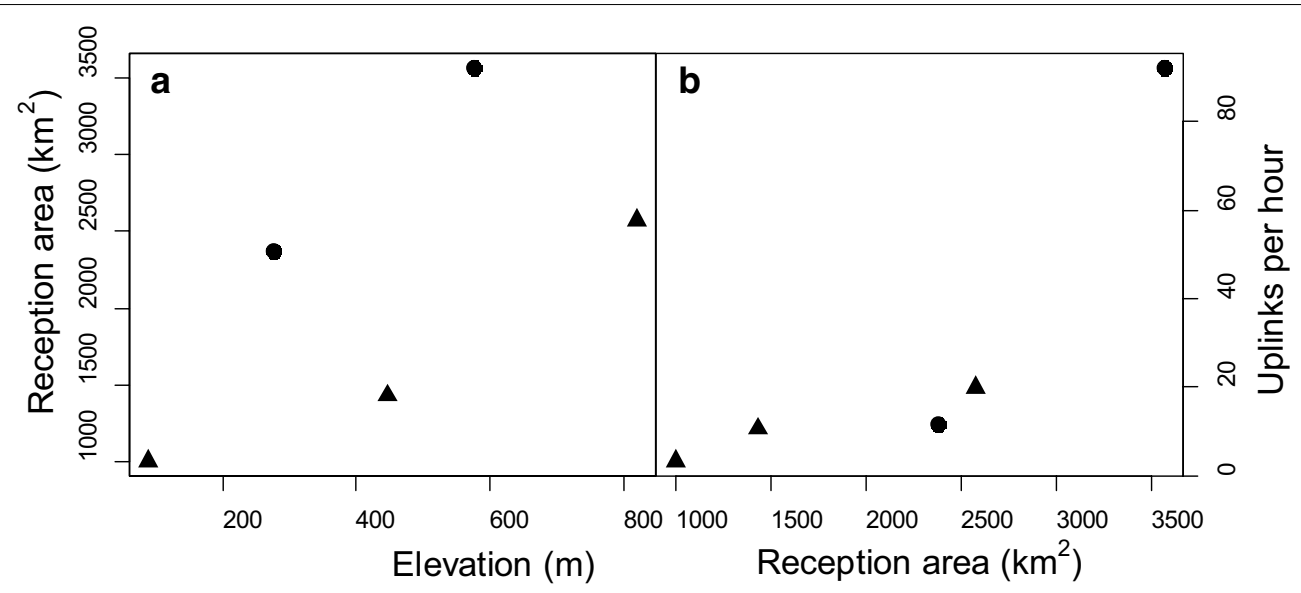

Fig. 4 a Relationship between elevation of Motes at their deployment site and Mote coverage areas (areas where Motes received 100\% of transmitted messages in $\mathrm{km}^{2}$ ) for Motes in the Hawaiian array (triangles) and the Southern California array (dots). Adjusted $R^{2}=0.90$ and $p=0.049$ for the linear regression for model with coverage area as the response variable, and elevation and Mote array location (Hawaii vs. Southern California) as explanatory variables $(n=5, d f 3)$. b Rate of uplink reception per hour as a function of the Mote coverage area and Mote array location. Adjusted $R^{2}=0.71$ and $p=0.071$ for the linear regression with uplinks per hour as the response variable and coverage area as explanatory variables $(n=5, d f$ 3)

for whales in Southern California (5.3 \pm 2.9 times more) compared to sharks around Hawaii $(4.0 \pm 3.2$ times more, $W=77, p=0.283)$. This translated into Motes receiving significantly more messages per hour than Argos satellite overall ( $W=395, p=0.027$, Table 2 ). This increase in message reception rate by Motes was significant for tagged whales in Southern California $(W=91, p=0.001)$ and tagged sharks in Hawaii $(W=107, p=0.045$, Table 2). Both Mote and Argos satellites logged more messages per unit of time for whales in southern California than for sharks in Hawaii $(W=9, p<0.001$ and $W=10, p<0.001$, respectively). Of these messages received, Motes successfully decoded significantly more messages than Argos satellites in Southern California ( $W=90, p=0.002$ ) but not significantly around Hawaii ( $W=88, p=0.370$, Table 2). On average, $13.2 \pm 9.8 \%$ of messages received by Motes were duplicates (received simultaneously by the two independent antennas), and $3.6 \pm 3.4 \%$ of messages were received both by Motes and Argos satellites.

The total number of messages received by both platforms varied by time of day (Fig. 6) for sharks and whales. Messages from tagged sharks around Hawaii showed a bimodal distribution with more messages received around $6.00-7.00$ a.m. and 5.00-6.00 p.m. local time independently of the receiving platform. Motes always logged more messages than Argos satellites but more so between 11.00 p.m. -1 a.m. and 9.00 a.m. -1.00 p.m. local time when Argos satellites logged very few to no messages. The distribution of received messages per time of day was more uniform for whales around Southern
California with a rapid peak at 4.00 p.m. and a decline at 7.00 a.m. local time (Fig. 6). Argos satellites received few to no message around 12.00-1.00 a.m. and 7.009.00 a.m. local time, while Motes continued to log messages during these times.

Four tags deployed on sharks (two SPOT6-F and two Bathygraph tags) logged GPS locations of the animals to transmit via Argos message. Motes logged most of the received locations $(96.0 \pm 5.6 \%)$, while Argos satellites only logged $26.2 \pm 10.0 \%(W=16, p=0.029)$ with an overlap of $23.0 \pm 9.6 \%$ of GPS locations received simultaneously by both systems. Times series of dive depths were recorded for three of the sharks for which Motes received $\sim 40 \%$ more dive depth data than Argos satellites (78.0 $\pm 26.7 \%$ vs. $37.1 \pm 17.5 \%$, respectively, not significant, $W=6, p=0.250$ ) with an overlap of $13.6 \pm 8.7 \%$ of total number of data points. Similarly, virtually all the mixed-layer depth data that were received from the two Bathygraph tags were logged by Motes (33 and 37 data points), while Argos satellites only logged one and two data points per tag, respectively. In Southern California, summarized vertical behaviors (dive type, dive depth, dive duration) were recorded for two fin and 10 Cuvier's beaked whales, and additional time-series of dive depths were recorded for the 10 Cuvier's beaked whales. Motes recorded a significantly greater proportion of all logged dives $(92.2 \pm 8.5 \%)$ than Argos satellites $(61.9 \pm 22.4 \%$ $W=74, p=0.002$ ), with $51.0 \pm 21.9 \%$ of dives logged by both platforms. Similarly, Motes recorded $\sim 32 \%$ more time-series dive depth data $(88.3 \pm 16.2 \%)$ than Argos satellites $(56.4 \pm 32.7 \%, W=55, p=0.005$, lower graphs 

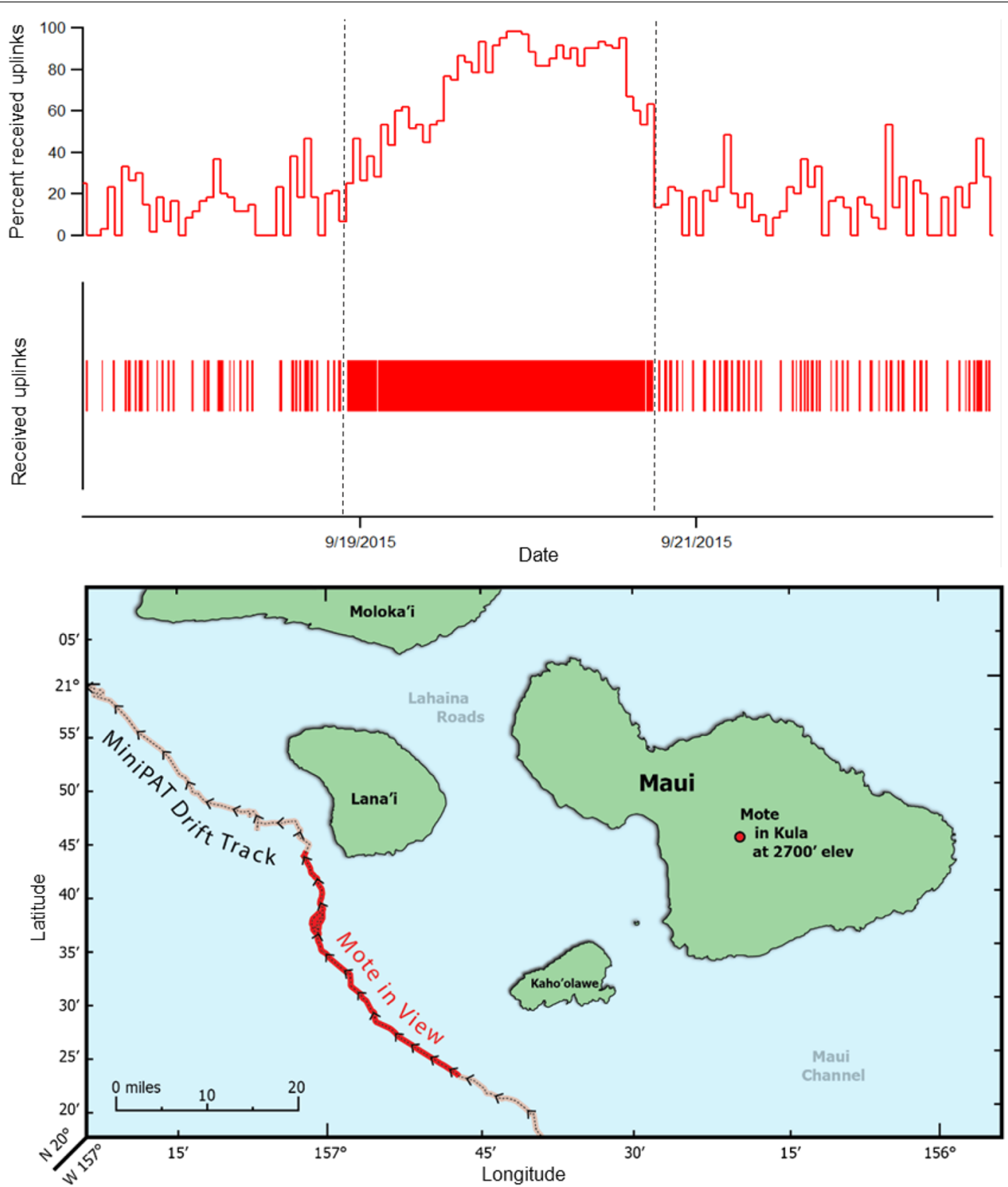

Fig. 5 Track of a MiniPAT tag that drifted in the line of sight of Mote 14X0003 on Maui Island (bottom graph), and number of received uplinks over time and percent of received uplinks when the Mote was in the coverage area compared when it was not (i.e., only Argos satellite reception, top graph)

of Fig. 6). Out of all time-series data points recorded, $43.2 \pm 26.3 \%$ were detected simultaneously by both platforms.

\section{Discussion}

Our results indicate that Motes can significantly augment the rate of successfully recovered data messages from tagged marine vertebrates within Mote reception range compared to Argos satellites alone. Studied motes received up to $100 \%$ of messages transmitted by tags when in direct line of sight (Fig. 5) and, at latitudes below $40^{\circ}$, induced an average of three- to fivefold increase (up to 12-fold) in data throughput compared to Argos satellites for case study animals (Fig. 6). As such, this technology has the potential to bridge gaps in our knowledge of marine animals' ecology, such as for the whales and sharks featured in this study, in relation to their physical and biological environments [19].

\section{Mote performances}

The relative benefit of Motes will likely be highest in regions of the world where Argos satellite availability is 
Table 2 Rate of message reception and of successful decoding of received messages (in \%) calculated for both receiving platforms overall (Motes and Argos satellites), or by location for whales in Southern California (SoCal) or sharks in Hawaii

\begin{tabular}{llllll}
\hline & \multicolumn{2}{l}{$\begin{array}{l}\text { Message reception } \\
\text { rate }(\mathrm{h})\end{array}$} & & \multicolumn{2}{l}{$\begin{array}{l}\text { Successful message } \\
\text { decoding (\%) }\end{array}$} \\
\cline { 2 - 3 } \cline { 6 - 7 } \cline { 5 - 6 } & Mote & Argos & & Mote & Argos \\
\hline Overall & $3.9 \pm 4.7^{*}$ & $0.8 \pm 0.8$ & & $93.2 \pm 11.7^{*}$ & $64.4 \pm 23.2$ \\
SoCal & $7.1 \pm 4.7^{*}$ & $1.2 \pm 0.4$ & & $86.5 \pm 10.4^{*}$ & $56.9 \pm 21.6$ \\
Hawaii & $1.0 \pm 3.0^{*}$ & $0.3 \pm 0.7$ & & $78.7 \pm 12.1$ & $68.2 \pm 25.1$ \\
\hline
\end{tabular}

* Significant differences between Motes and Argos platforms ( $n=12$ for whales in SoCal and $n=12$ for sharks in Hawaii, Wilcoxon rank-sum test)

lowest. The orbit patterns of the satellites carrying Argos receivers are such that satellite availability is lowest at low latitudes (near the equator) and improves towards the poles (Fig. 1). For example, the probability of successful reception of a message set up to be re-transmitted six times is $\sim 0.5$ at latitudes below $40^{\circ}$ (Additional file 1: Fig. S1), so the presence of Motes would double the chances of successfully logging this message (probability of Mote reception within its range is close to 1 ). At the poles, the probability of reception by Argos satellites is already close to $\sim 0.9-1$, so the benefit would theoretically be insignificant. However, if the surfacing behavior of tagged animals is such that messages can only be transmitted once or twice, the probability at low latitudes drops to $\sim 0.15$. Motes could then multiply the data return by 6 (or by 2 at the poles where probability is now only 0.45 -Fig. 1 ). There is thus a trade-off between quantity of data transmitted and likelihood it will get successfully received by one or the other of the systems-and this is dependent on the latitude of the study site and the surfacing behavior of the study species. If animals are expected to remain mostly around Motes, it might be less advantageous to

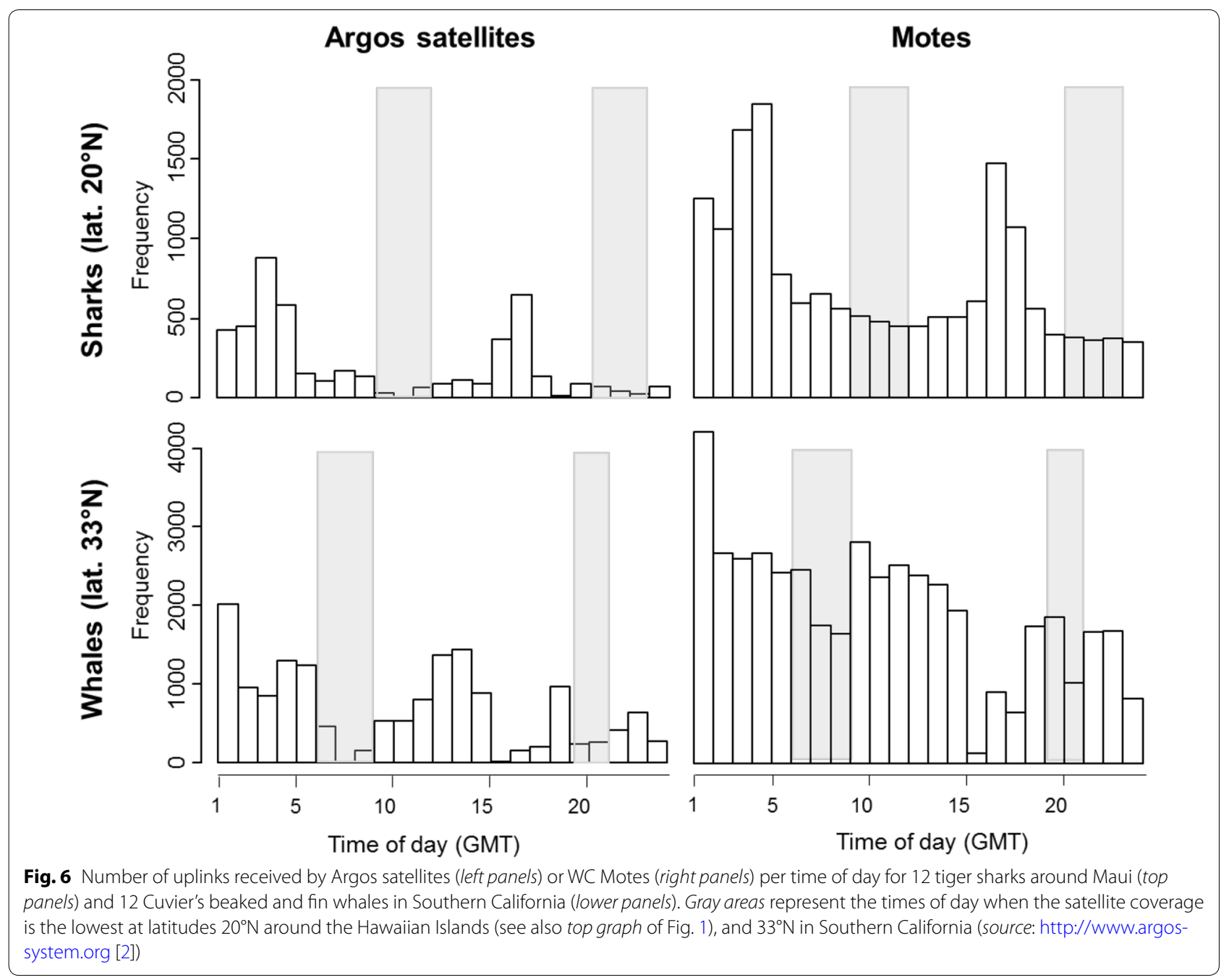


program tags for a high number of message re-transmits that would be more suited to "satellite-only" experimental design. In scenarios where Motes are operative, tags could be programmed to be less repetitive and thus more information could be transmitted per unit of time, which would also contribute to higher data return.

In addition, Motes did not show diel temporal variation in their capacity to collect data and so have the potential to fill in the blanks during the times of day when satellite coverage is not available (Fig. 1). For example, there were $\sim 1-2 \mathrm{~h}$ gaps in satellite availability twice a day around Hawaii and Southern California when very little to no data were collected via satellite (Fig. 6). On the other hand, Motes continued collecting data dictated by the rate of surfacing behavior of the animals. For example, lower rates in data collection during the two-time gaps in satellite coverage were not due to lower surfacing activity of whales (Fig. 6). On the other hand, shark data collected by Motes confirmed the bimodal distribution in their surfacing behavior around dawn and dusk and that they do not surface more often at night during the gaps in satellite coverage as could have been suspected simply from the Argos coverage.

Within their reception range, Motes are capable of collecting more data and provide behavioral and environmental data at a much finer scale spatially and temporally than Argos satellites alone (Figs. 6, 7). For example, Motes received up to 3.5 times more recorded dives than Argos satellites. In the absence of data acquired through the Motes, habitat selection for the tiger shark shown in Fig. 7 could be construed to depths of less than $200 \mathrm{~m}$ (and temperatures higher than $17^{\circ} \mathrm{C}$, not shown), whereas Mote data showed that the shark dove to $300 \mathrm{~m}$ (and temperatures of $9^{\circ} \mathrm{C}$ ). Spatially, Motes logged 96\% of the GPS locations recorded by tags, which means that not only did the additional locations provide a much more complete picture of where, when and how sharks use their environment, but as GPS locations are more accurate than Argos locations, the uncertainty around animal's movements was also reduced [12, 24]. Consequently, Motes have the potential to improve our knowledge of whales and sharks' behaviors both quantitatively and qualitatively.

\section{Factors affecting Motes performance}

Although Motes greatly increased data recovery from satellite-relayed tags, their individual performances varied with the characteristics of their deployment site, i.e., the elevation of the Motes, presence of obstacles in their line of sight, and the orientation of the antennas. Predictably, Motes deployed at greater elevations showed larger coverage areas and longer maximum distances of reception (Fig. 3). We are aware that the low sample size of five
Motes limits the power and reliability of linear regressions performed in this preliminary study. Nevertheless, even a qualitative assessment of the data seems to indicate that the underlying trends match expectations: because elevation overcomes the curvature of the earth and other potential obstacles in the line of sight [25], higher Motes understandably received more messages per unit of time when coverage areas and reception distances increased (Fig. 4). In addition to elevation, Motes' capabilities at receiving PTT signals were also affected by obstacles in their line of sight. Coverage area of Motes in Hawaii-with Kaho'Olawe and Lana'i Islands in the south and the Pu'ukukui mountains northeast-was relatively smaller than in Southern California-where no physical obstacles are present-even though Mote 14X0003 was deployed at the highest elevation of all (Fig. 3; Table 1). If the topographic constraints cannot be overcome, orientation of the two receiving antennas can be adjusted to control which areas are covered and maximize data return given the species of study. Coverage is maximized in line with the direction of the antennas and within the overlap area between them (antennas are redundant). Not surprisingly, the furthest message received by each Mote was roughly aligned with the direction of one of the antennas (Fig. 3).

It is interesting to note that the number of messages received by Motes and uplink rates was much higher from whales in Southern California than from sharks in Hawaii (Fig. 6). Motes in Southern California logged $\sim 7$ times more messages per unit of time than Argos satellites, while the increase was only threefold in Hawaii for sharks. It is difficult to determine whether this difference was a consequence of the Mote array deployment characteristics (i.e., a greater coverage area in Southern California), whether it was due to the behavior of animals, or both. Indeed, as air-breathers, whales need to come to the surface at much more regular intervals than sharks do and consequently expose their tags to receiving systems more frequently. Even though coverage area is an important factor, biology of the study animals and their surfacing behavior likely also affect the level of improvement of data return that Motes provide.

\section{Limitations}

The main limitation of Motes comes from their stationary nature; they can only receive data transmitted within their reception range which in turn is dependent on elevation. This limitation will be more difficult to overcome for highly mobile species, but it will ultimately depend on the behavior of the studied species and the scientific questions being addressed. However, data collection protocols of the tag can be modified specifically to maximize likelihood of data recovery. It is also important to 


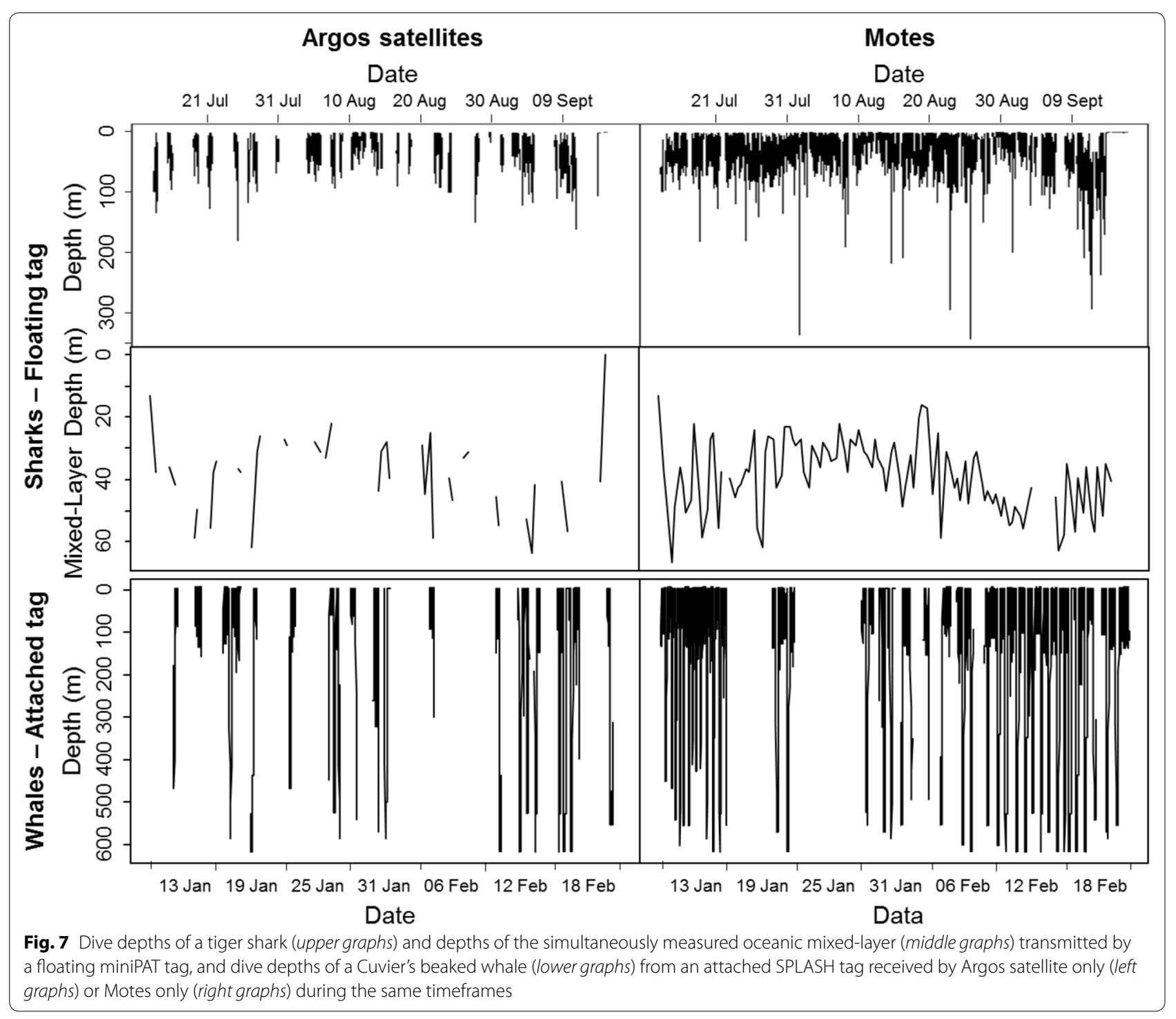

point out that Motes can log messages containing data recorded during periods of time while outside of their covering area, and are as such logging behaviors beyond their range.

Unlike the Argos system, Mote units will not be able to detect truly open ocean movements (unless mounted to ships). For example, neither Motes in the Southern California Bight recorded dive data on January 25 (3rd day) for the whale shown in Fig. 7 as the animal left the Mote coverage area, while Argos satellites did. Also, unlike Argos satellites that make use of the Doppler effect created by their orbital movement to estimate locations of transmitting devices, Motes do not have the ability to determine the location of transmitting tags unless those tags also possess some form of GPS or other geolocation capability. Nevertheless, simply knowing that a transient animal is within a Mote's "footprint" can provide useful information about widely ranging animals - such as those making transoceanic or long distance alongshore movements (e.g., gray whales in the Eastern Pacific).

Finally, the capacity of Motes at receiving multiple messages simultaneously is limited. If too many tags are present within the coverage area, interference between signals transmitted at the same time could corrupt the messages, in which case none of the signals would be usable (similar to Argos system). The number of tags beyond which Motes would overload depends on their transmission rate and duty cycle. Some of the Motes within the two arrays we studied logged messages from hundreds of different devices, and up to $\sim 90$ messages per hour (the two redundant antennas can log different messages at the same time). In any case, the best strategy to maximize 
data return and overall performance of Motes is to create a good balance between the number of receiving antennas and the number of transmitting devices.

\section{Implications}

Marine environments are facing rapid changes worldwide. As a consequence, research and management strategies have shifted towards a more holistic and ecosystem-based approach [1]. Despite these efforts, the lack of quality-and quantity-of ecological datasets limits usefulness of spatially explicit or predictive models-such as habitat preference or distribution models $[8,18,22$, 38]. Consequently, our understanding of the ecological impacts of these physical changes remains insufficient [23]. We have demonstrated that Motes can increase the quantity of data collected within their reception range and as such they can contribute to a deeper understanding of biology and ecology of marine animals. Importantly, because of the increased amount of data that can be acquired, it becomes possible to acquire much more in situ information from animals regarding their habitat preferences and responses to the physical world around them. Motes can help bridge gaps in the information needed for sound research and sustainable management, which falls within national and international directives for ecosystem research [1].

Motes are also non-discriminatory-within their reception range they collect and log PTT messages from any Argos-relayed device (and from any tag manufacturer) while still keeping the messages private between data owners. Scenarios are possible wherein multiple users can get access to their data collected by Motes at no additional cost even if the structures belong to another research group. As such, Motes can benefit a much wider community of scientists. They have the potential to increase opportunities of research collaborations and facilitate creation of consortiums between specialists in diverse fields of investigation with a common interest of telemetry-based ecological research. Collaborative installations of extensive arrays of Motes at key locations throughout a coast line or over islands or archipelagos could significantly improve "cost per unit effort" of tagging studies for coastal animals. For example, Mote arrays might be comprised of units underwritten by funding from multiple agencies and institutions (as were the Motes in Hawaii used in this study). This type of collaboration is increasingly facilitated through organizations such as the Ocean Tracking Network or the Animal Tracking Network in North America and the Integrated Marine Observing System in Australia. Mote arrays could help fill in gaps from the current spatially "patchy" research effort [35] and thus enhance the resulting quality of research output. In addition to increasing productivity [28], collaborative projects are a requisite from many funding agencies, and as such these consortiums are likely to appeal to funders for both small- and large-scale grants $[5,13]$. However, because the data collected by Motes are not necessarily associated with their owners name or with information on what the transmitting device was deployed on, an ethical code of conduct should be developed to maximize the integrity of this new way of collecting messages from satellite-linked devices [9].

Future applications could also include standardized deployments of mobile Motes on board ships to extend the arrays to the open ocean and collect data at a greater rate from non-shore animals as well. Short-term deployments on drones in key locations are also a possibility. Large-scale arrays of Motes could benefit a wide range of studies such as on migratory animals or on shifts in migration patterns due to environmental changes. This could open the door to greater quantity of data collected in high seas where animals are usually more elusive and potentially more difficult to study and thus a better quality of resulting datasets. For example, West Indian manatees (Trichechus manatus) are endangered coastal marine mammals ranging from northeastern Brazil to NorthCarolina (USA) that migrate yearly along the Atlantic coast to remain within a thermal zone above $20{ }^{\circ} \mathrm{C}[10]$. Recent success in tagging manatees opened the door to the use of satellite-relayed telemetry data for this species with a consequence of a better understanding of their habitat preference and movement patterns, a key to conservation management [16]. If motes were installed along their migratory routes, they could provide more information-and at a much finer scale-on environment characteristics as well as on spatial and temporal movements and behavior of tagged animals than the traditional Argos system. They could also help coordinating efforts within and across countries or research teams along manatees' distribution range. As another example, improvement in conservation strategies could be forecasted for fin and Cuvier's beaked whales, two species for which there is a fundamental lack of fine-scale data, and whose distribution ranges in southern California covers areas of intense human activities including navy testing and training activities [14]. In any case, the range of potential applications to the use of Motes is as large as the panel of usage of satellite-relayed telemetry whether related to physiology, energetics, behaviors, life history, ecology or links between environment and animals $[4,33]$.

\section{Conclusions}

This preliminary study showed that Motes are capable of greatly enhancing successful reception of satelliterelayed signals and thus improve both the quality and the 
quantity of telemetry-based physical and biological datasets compared to the traditional Argos satellites system. They consequently contribute to bridging gaps in knowledge of biology and ecology of animals and ecosystems, of the mechanisms by which one affects the other, and of their conservation and management. In their current form, they are mostly limited to coastal areas, but evolution and development of the system could lead to more mobile arrays. The clear benefits that can be drawn from such non-discriminatory high data-throughput-receiving systems are likely to interest the scientific community, to help coordinating research effort, and to hopefully trigger large-scale high-quality collaborative projects to ultimately improve marine ecosystem conservation and management.

\section{Additional file}

\begin{abstract}
Additional file 1: Doc S1. Technical specifications of Motes. Figure S1: Probability of successful reception of a PTT signal by Argos satellites given the number of times it is re-transmitted at different latitudes from the Equator (in blue) to the poles (in black). Probabilities for successive transmissions were calculated using the probabilities in lower Figure 1 for a single transmission (Source: http://www.argos-system.org, [2]). Table S1: Details on the telemetry data used for preliminary analyses of Mote performances including type of tag, deployment duration, and type of data collected for sharks around the Hawaiian Islands and Cuvier's beaked whales and fin whales in Southern California.
\end{abstract}

\section{Authors' contributions}

TJdD summarized data, performed all analyses and wrote the manuscript. KH and GS provided the shark and whale data, respectively. DV was involved with the development of Motes at Wildlife Computers ${ }^{\mathrm{TM}}$ and provided technical details on the Motes as well as help with data manipulation and analyses. All authors contributed to interpretation of results and research concepts. All authors read and approved the final manuscript.

\section{Author details}

${ }^{1}$ Wildlife Computers, 8345 154th Avenue NE, Redmond, WA 98052, USA.

${ }^{2}$ Hawaii Institute of Marine Biology, University of Hawaii, Honolulu, HI, USA.

${ }^{3}$ Marine Ecology and Telemetry Research, 2420 Nellita Rd NW, Seabeck, WA 98380, USA. ${ }^{4}$ Present Address: Department of Fisheries and Oceans, Institut Maurice Lamontagne, P.O. Box 1000, 850 Route de la Mer, Mont-Joli, QC G5H 3Z4, Canada.

\section{Acknowledgements}

Thanks to Heidi Nevitt, Robert Tahimic, Bill Kimbal, Dean Yamashita, John Ugoretz and Dave Moretti for help installing and maintaining the Motes in Southern California, and thanks to Erin Falcone and the SCORE crew for assistance with field work. Thanks to Mark and Ali Minney and Donna Brown for providing locations for Motes on Maui Island, as well as to Wildlife Computers $^{\mathrm{TM}}$ Inc, Redmond, Washington for their in-kind support.

\section{Competing interests}

Motes were developed and commercialized by Wild life Computers ${ }^{\mathrm{TM}}$. TJdD was contracted by Wildlife Computers ${ }^{\mathrm{TM}}$ as a short-term researcher to lead this independent validation and performance study. DV is a permanent employee of Wildlife Computers ${ }^{\mathrm{TM}}$.

\section{Availability of data and materials}

Date/time, PTT IDs, Location, Location Class Information and presence or absence of data collected by Motes and Argos systems will be stored and made available on the cloud of the Wild life Computers Data Portal following the approval of the pertinent author.

\section{Ethics approval}

All appropriate ethics permissions were obtained prior to commencement of this work. Tagging of whales in Southern California was conducted under NOAA research permits 540-1811 and 16111 and conducted under the Cascadia Research Collective's Institutional Animal Care and Use Committee. Tagging of sharks around Hawaiian Islands was conducted under the University of Hawaii IACUC protocol \# 05-053-10.

\section{Funding}

Funding for work in Southern California was provided by the US Navy, including N45, the Living Marine Resources program, and the Pacific Fleet which provided funding for the Motes, fieldwork and tags. Financial support for the work around Hawaiian Islands was provided by PaclOOS which is a part of the US Integrated Ocean Observing System $\left(\right.$ IOOS $\left.^{\circledR}\right)$, funded in part by the National Oceanic and Atmospheric Administration (NOAA) Awards \#NA11NOS0120039 and \#NA16NOS0120024. Funding was also provided by the State of Hawaii Division of Aquatic Resources, Department of Land and Natural Resources. The funders had no role in study design, data collection and analysis, decision to publish, or preparation of the manuscript.

\section{Publisher's Note}

Springer Nature remains neutral with regard to jurisdictional claims in published maps and institutional affiliations.

Received: 28 February 2017 Accepted: 23 June 2017

Published online: 11 July 2017

\section{References}

1. Apitz SE, Elliott M, Fountain M, Galloway TS. European environmental management: moving to an ecosystem approach. Integr Environ Assess Manag. 2006;22:80-5

2. Argos System - CLS - Satellite Pass Prediction 2016. http://www.argossystem.org. Accessed 06 Aug 2016.

3. Block BA, Holbrook CM, Simmons SE, Holland KN. Toward a national animal telemetry network for aquatic observations in the United States. Anim Biotelemetry. 2016;4:6.

4. Bograd SJ, Block BA, Costa DP, Godley BJ. Biologging technologies: new tools for conservation. Introduction. Endanger Species Res. 2010;10:1-7.

5. Bozeman B, Corley E. Scientists' collaboration strategies: implications for scientific and technical human capital. Res Policy. 2004;33:599-616.

6. Carretta JV, Forney KA, Lowry MS, Barlow J, Baker J, Hanson B, Muto MM. U.S. Pacific Marine Mammal Stock Assessments: 2007. NOAA Technical Memorandum, US Department of Commerce; 2007, p. 320.

7. Cermeño P, Quílez-Badia G, Ospina-Alvarez A, Sainz-Trápaga S, Boustany AM, Seitz AC, Tudela S, Block BA. Electronic tagging of Atlantic bluefin tuna (Thunnus thynnus, L.) reveals habitat use and behaviors in the Mediterranean Sea. PLoS ONE. 2015;10:e0116638.

8. Chrysafi A, Kuparinen A. Assessing abundance of populations with limited data: lessons learned from data-poor fisheries stock assessment. Environ Rev. 2015:24:25-38.

9. Culnan MJ, Clark Williams C. How ethics can enhance organizational privacy: lessons from the choicepoint and TJX data breaches. MIS Q. 2009;33:673-87.

10. Deutsch CJ, Reid JP, Bonde RK, Easton DE, Kochman HI, O'Shea TJ. Seasonal movements, migratory behavior, and site fidelity of West Indian manatees along the Atlantic coast of the United States. Wildl Monogr. 2003;151:1-77.

11. Dewar H, Prince ED, Musyl MK, Brill RW, Sepulveda C, Luo J, Foley D, Orbesen ES, Domeier ML, Nasby-Lucas N, Snodgrass D, Michael Laurs R, Hoolihan JP, Block BA, McNaughton LM. Movements and behaviors of swordfish in the Atlantic and Pacific Oceans examined using pop-up satellite archival tags. Fish Oceanogr. 2011;20:219-41. 
12. Dragon AC, Bar-Hen A, Monestiez P, Guinet C. Comparative analysis of methods for inferring successful foraging areas from Argos and GPS tracking data. Mar Ecol Prog Ser. 2012;452:253-67.

13. Ebadi A, Schiffauerova A. How to receive more funding for your research? Get connected to the right people! PLoS ONE. 2015;10:e0133061.

14. Falcone EA, Schorr GS, Douglas AB, Calambokidis J, Henderson E, McKenna MF, Hildebrand J, Moretti D. Sighting characteristics and photo-identification of Cuvier's beaked whales (Ziphius cavirostris) near San Clemente Island, California: a key area for beaked whales and the military? Mar Biol. 2009;156:2631-40.

15. Fancy SG, Pank LF, Douglas DC, Curby CH, Garner GW, Amstrup SC, Regelin WL. Satellite telemetry: a new tool for wild life research and management. Washington: Resource Publication, US Fish and Wildlife Services; 1988. p. 61.

16. Gonzalez-Socoloske D, Olivera-Gómez LD, Reid JP, Espinoza-Marin C, Ruiz $\mathrm{KE}$, Glander KE. First successful capture and satellite tracking of a West Indian manatee (Trichechus manatus) in Panama: feasibility of capture and telemetry techniques. Latin Am J Aquat Mamm. 2015. doi:10.5597/ lajam00194.

17. Guinet C, Vacquié-Garcia J, Picard B, Bessigneul G, Lebras Y, Dragon A, Viviant M, Arnould J, Bailleul F. Southern elephant seal foraging success in relation to temperature and light conditions: insight into prey distribution. Mar Ecol Prog Ser. 2014;499:285-301.

18. Guisasola A, Baeza JA, Carrera J, Sin G, Vanrolleghem PA, Lafuente J. The influence of experimental data quality and quantity on parameter estimation accuracy. Educ Chem Eng. 2006;1:139-45.

19. Harley CDG, Randall Hughes A, Hultgren KM, Miner BG, Sorte CJB, Thornber CS, Rodriguez LF, Tomanek L, Williams SL. The impacts of climate change in coastal marine systems. Ecol Lett. 2006;9:228-41.

20. Hart KM, Hyrenbach KD. Satellite telemetry of marine megavertebrates: the coming of age of an experimental science. Endanger Species Res. 2009;10:9-20.

21. Heide-Jorgensen M, Nordoy E, Oien N, Folkow L, Kleivane L, Blix A, Jensen M, Laidre K. Satellite tracking of minke whales (Balaenoptera acutorostrata) off the coast of northern Norway. J Cetacean Res Manag. 2001;3:175-8.

22. Hirzel AH, Helfer V, Metral F. Assessing habitat-suitability models with a virtual species. Ecol Model. 2001;145:111-21.

23. Hoegh-Guldberg O, Bruno JF. The impact of climate change on the world's marine ecosystems. Science. 2010;328:1523-8.

24. Hoenner X, Whiting SD, Hindell MA, MCMahon CR. Enhancing the use of argos satellite data for home range and long distance migration studies of marine animals. PLoS ONE. 2012;7:e40713.

25. Holis J, Pechac P. Elevation dependent shadowing model for mobile communications via high altitude platforms in built-up areas. IEEE Trans Antennas Propag. 2008;56:1078-84.

26. Hussey NE, Kessel ST, Aarestrup K, Cooke SJ, Cowley PD, Fisk AT, Harcourt RG, Holland KN, Iverson SJ, Kocik JF, Mills Flemming JE, Whoriskey FG. Aquatic animal telemetry: a panoramic window into the underwater world. Science. 2015;348:1221.

27. Jeanniard du Dot T, Trites AW, Arnould JPY, Speakman JB, Guinet C. Flipper strokes can predict energy expenditure and locomotion costs in free-ranging northern and Antarctic fur seals. Sci Rep. 2016;6:33912.

28. Lee S, Bozeman B. The impact of research collaboration on scientific productivity. Soc Stud Sci. 2005;35:673-702.
29. Lutcavage ME, Lam CH, Galuardi B. Seventeen years and $\$ 3$ million dollars later: performance of PSAT tags deployed on Atlantic bluefin and bigeye tuna. Col Vol Sci Pap ICCAT. 2015;71:1757-65.

30. Mate B, Best PB. Coastal and offshore movements of southern right whales on the South African coast revealed by satellite telemetry. Rep Int Whal Comm SC/60/BRG8; 2008.

31. Musyl MK, Domeier ML, Nasby-Lucas N, Brill RW, McNaughton LM, Swimmer JY, Lutcavage MS, Wilson SG, Galuardi B, Liddle JB. Performance of pop-up satellite archival tags. Mar Ecol Prog Ser. 2011;433:1-28.

32. Ockendon N, Baker DJ, Carr JA, White EC, Almond REA, Amano T, Bertram E, Bradbury RB, Bradley C, Butchart SHM, Doswald N, Foden W, Gill DJC, Green RE, Sutherland WJ, Tanner EVJ, Pearce-Higgins JW. Mechanisms underpinning climatic impacts on natural populations: altered species interactions are more important than direct effects. Glob Change Biol. 2014:20:2221-9.

33. Payne NL, Taylor MD, Watanabe YY, Semmens JM. From physiology to physics: are we recognizing the flexibility of biologging tools? J Exp Biol. 2014:217:317-22.

34. Pohlot BG, Ehrhardt N. An analysis of sailfish daily activity in the Eastern Pacific Ocean using satellite tagging and recreational fisheries data. ICES $J$ Mar Sci 2017;fs ×082.

35. Richardson AJ, Brown CJ, Brander K, Bruno JF, Buckley L, Burrows MT, Duarte CM, Halpern BS, Hoegh-Guldberg O, Holding J, Kappel CV, Kiessling W, Moore PJ, O'Connor MI, Pandolfi JM, Parmesan C, Schoeman DS, Schwing F, Sydeman WJ, Poloczanska ES. Climate change and marine life. Biol Lett. 2012;8:907-9.

36. Royer MA, Holland KN. Spatial dynamics of tiger sharks (Galeocerdo cuvier) around. In: Maui, Oahu. (ed. R.t.t.H.D.o.L.a.N. Resources). Hawaii Institute of Marine Biology - University of Hawaii at Manoa, Hawaii; 2016.

37. Schorr GS, Falcone EA, Moretti DJ, Andrews RD. First long-term behavioral records from Cuvier's beaked whales (Ziphius cavirostris) reveal recordbreaking dives. PLoS ONE. 2014;9:e92633.

38. Smith D, Punt A, Dowling N, Smith A, Tuck G, Knuckey I. Reconciling approaches to the assessment and management of data-poor species and fisheries with Australia's harvest strategy policy. Mar Coast Fish. 2009; 1:244-54

39. Thys TM, Ryan JP, Dewar H, Perle CR, Lyons K, O'Sullivan J, Farwell C, Howard MJ, Weng KC, Lavaniegos BE, Gaxiola-Castro G, Miranda Bojorquez $L E$, Hazen EL, Bograd SJ. Ecology of the Ocean Sunfish, Mola mola, in the southern California Current System. J Exp Mar Biol Ecol. 2015;471:64-76.

40. Wilmers CC, Nickel B, Bryce CM, Smith JA, Wheat RE, Yovovich V. The golden age of bio-logging: how animal-borne sensors are advancing the frontiers of ecology. Ecology. 2015;96:1741-53.

41. Wright BM, Ford JKB, Ellis GM, Deecke VB, Shapiro AD, Battaile BC, Trites AW. Fine-scale foraging movements by fish-eating killer whales (Orcinus orca) relate to the vertical distributions and escape responses of salmonid prey (Oncorhynchus spp.). Mov Ecol. 2017;5:3.

\section{Submit your next manuscript to BioMed Central and we will help you at every step:}

- We accept pre-submission inquiries

- Our selector tool helps you to find the most relevant journal

- We provide round the clock customer support

- Convenient online submission

- Thorough peer review

- Inclusion in PubMed and all major indexing services

- Maximum visibility for your research

Submit your manuscript at www.biomedcentral.com/submit 